\title{
Erratum to: Complexes of hybrid copolymers with heavy metals: preparation, properties and application as catalysts for oxidation
}

\section{Sevdalina Chr. Turmanova ${ }^{1}$ Ivaylo V. Dimitrov ${ }^{2}$.}

Emilya D. Ivanova ${ }^{1,2} \cdot$ Krassimir G. Vassilev $^{1}$

\section{Erratum to: Polym. Bull.}

\section{DOI 10.1007/s00289-015-1338-z}

Unfortunately, in the original publication, Fig. 9 has been incorrectly published. The corrected figure is given below:

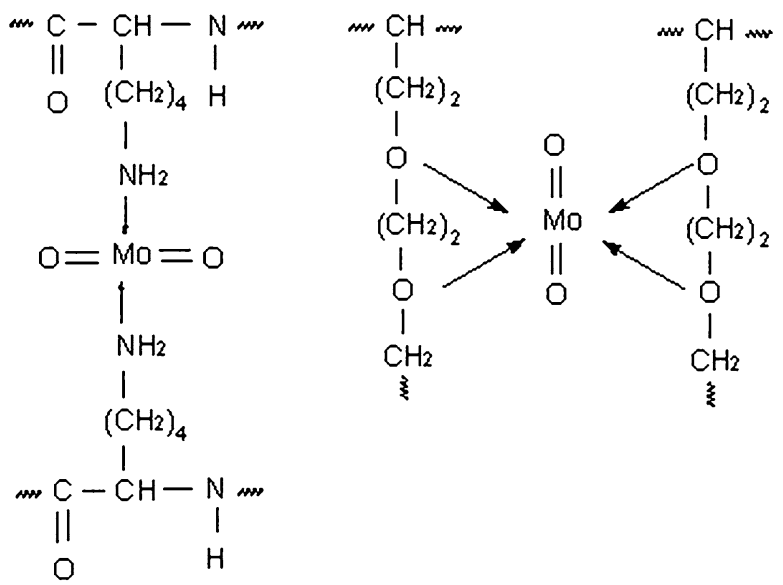

\footnotetext{
The online version of the original article can be found under doi:10.1007/s00289-015-1338-z.
}

Sevdalina Chr. Turmanova

sturmanova@btu.bg

1 Assen Zlatarov University, 1 Y. Yakimov St, 8010 Burgas, Bulgaria

2 Institute of Polymers, Bulgarian Academy of Sciences, 1113 Sofia, Bulgaria 